\title{
The Current Impact of Entry-Level Associate and Baccalaureate Degree Education on the Diversity of Respiratory Therapists
}

\author{
Ellen A Becker PhD RRT-NPS RPFT AE-C FAARC and Xuan T Nguyen MSc RRT
}

\begin{abstract}
INTRODUCTION: Transitioning from an associate degree to a baccalaureate degree for respiratory therapists has been suggested as a new entry-level educational standard. One potential risk for this change is that it may limit the diversity of potential applicants for entry-level education. A diverse workforce is important to achieve the goal of reducing healthcare disparities. This study evaluated characteristics of therapists who completed associate and baccalaureate degree entrylevel education. METHODS: A secondary analysis of data collected from the 2009 AARC Respiratory Therapist Human Resource Survey explored relationships between the choice of entry-level associate or baccalaureate education and variables of gender, race, salary, career advancement, and job satisfaction. RESULTS: There were no differences between therapists with entry-level associate and baccalaureate degrees in gender, race, number of additional healthcare credentials, numbers of life support credentials, wages, delivering respiratory care by protocol, and job satisfaction. There were significantly higher percentages of advanced academic degrees, desire to pursue a higher academic degree, registered respiratory therapist credentials, total National Board for Respiratory Care credentials, and leadership roles for therapists with baccalaureate entry-level degrees. CONCLUSIONS: Current entry-level associate and baccalaureate degree graduates have similar gender and race proportions. This finding challenges concerns that an entry-level baccalaureate degree would decrease the diversity of the respiratory therapist workforce. Key words: respiratory care; respiratory therapist; diversity; education; training; credentials. [Respir Care 2014;59(12):1817-1824. (C) 2014 Daedalus Enterprises]
\end{abstract}

\section{Introduction}

Respiratory therapists care for patients with both acute and chronic breathing problems across the entire age spectrum. According to the Bureau of Labor Statistics, respiratory therapy is one of the fastest growing allied health-

Dr Becker is affiliated with the Department of Cardiopulmonary Sciences, Rush University, Chicago, Illinois, and Mr Nguyen is affiliated with Park Nicollet Methodist Hospital, St. Louis Park, Minnesota.

Mr Nguyen and Dr Becker presented an abstract of this research at AARC Congress 2013, held November 16-19, 2013, in Anaheim, California.

The authors have disclosed no conflicts of interest.

Correspondence: Ellen A Becker PhD RRT-NPS RPFT AE-C FAARC, Rush University, Armour Academic Center, Suite 750, 600 South Paulina Street, Chicago, IL 60612. E-mail: Ellen_Becker@rush.edu.

DOI: $10.4187 /$ respcare.03106 care professions and is expected to increase by $28 \%$ from 2010 to 2020 (http://www.bls.gov/ooh/healthcare/respira tory-therapists.htm, Accessed November 10, 2013). The Commission on Accreditation for Respiratory Care accredits respiratory care education programs that offer a minimum of an associate degree (http://www.coarc.com/ 29.html, Accessed March 23, 2014). In 2011, the associate

See the Related Editorial on Page 1949

degree was the most common degree offered by $384(86 \%)$ of 444 accredited respiratory care programs. A baccalaureate degree was offered by $59(11 \%)$ of the programs. Currently, there are 381 (87\%) programs that award associate degrees and 57 programs $(13 \%)$ that award baccalaureate respiratory degrees. Thus, the associate degree, usually awarded by community colleges, continues to provide the most common path to obtain entry-level education for respiratory care in the United States. 
A series of conferences, titled 2015 and Beyond, were convened to look at the required skills and education needed for future respiratory care practice. One recommendation from the third conference in the series was to increase the entry-level education of respiratory therapists to a baccalaureate degree. ${ }^{1}$ This shift toward advanced degrees parallels a similar movement in nursing. Outcomes research related to surgical patients in the United States showed that care provided by nursing staff with a greater percentage of baccalaureate degrees at magnet hospitals had a $14 \%$ reduction in the odds of in-patient death within 30 days $^{2}$ and lower mortality and failure-to-rescue rates of surgical cancer patients. ${ }^{3,4}$ In Canada, 2 studies addressing the care of adult medical patients showed a relationship between decreased 30-d mortality when cared for by baccalaureate nurses. ${ }^{5,6}$ Building upon the findings from outcomes research, the Institute of Medicine recommended that the number of nurses with baccalaureate degrees be increased from the present level of $50 \%$ to $80 \%$ by 2020 . The same report suggested that nurses without baccalaureate degrees should enter degree programs within $5 \mathrm{y}$ of graduating from their associate or diploma programs.

Raising the entry-level education of respiratory therapists to a baccalaureate degree may provide similar benefits to patients. The American Association for Respiratory Care (AARC) encouraged development of baccalaureate and higher educational degree programs in respiratory care to meet the demands of providing services requiring complex cognitive abilities and patient management skills (http://www.aarc.org/resources/position_statements/ education.html, Accessed November 10, 2013). ${ }^{1}$ To date, however, no outcomes research with care provided by therapists who have predominately baccalaureate degrees has been conducted.

Disparities in gender, race, and socioeconomic status exist among baccalaureate degree graduates across all academic degrees. ${ }^{7,8}$ These disparities could prevent potential respiratory therapy applicants from pursuing baccalaureate degrees. Thus, changing to an entry-level baccalaureate degree could negatively impact the diversity of the profession's applicant pool. After World War II, men completed bachelor's degrees more frequently than women. ${ }^{9}$ This trend shifted around $1980 . \cdot^{9-12}$ By 2003, the ratio of women to men who completed their bachelor's degree was 1.35 to $1 .{ }^{9}$ Women completed the greatest numbers of bachelor's degrees across all racial categories. ${ }^{13}$

Minority healthcare providers are more likely to work in underserved areas and serve minority clients. The Sullivan Commission on Diversity in the Healthcare Workforce noted that $25 \%$ of the United States population was composed of African Americans, Hispanic Americans, and Native Americans. However, the percentages of nurses (9\%), physicians (6\%), and dentists (5\%) from these minority

\section{QUICK LOOK}

\section{Current knowledge}

The 2015 and Beyond conferences have recommended that a baccalaureate degree should be the new entrylevel educational standard. The impact of this recommendation on diversity of the profession and job satisfaction has not been determined.

\section{What this paper contributes to our knowledge}

A survey of current entry-level associate and baccalaureate degree graduates demonstrated similar race and gender proportions. These data suggest that the move to an entry-level baccalaureate standard would not negatively impact diversity of the workforce.

groups do not mirror the nation's diversity. Data on respiratory therapists were not reported. This current shortage of minority healthcare professionals was cited as a potentially significant contributor to the nation's healthcare disparities. ${ }^{14}$ Regarding education in minority populations, African-American and Hispanic students are more likely to attend community colleges than 4 -y institutions. ${ }^{15}$ Consistent with these data, white and Asian students complete more bachelor's degrees than their African-American, Hispanic, and Native American counterparts. The lower numbers for the latter groups result from both lower enrollment as well as persistence once enrolled. ${ }^{16}$ Although race is often reported in higher education disparities, the largest differences in graduation are affected more by other variables that correlate with race such as lower family income. ${ }^{17,18}$

An individual's socioeconomic status (SES) is affected by the relationship among biological and social factors. This complex relationship has 2 aspects. The first aspect is resources, such as education, income, and wealth. The second aspect is social rank, such as social class. ${ }^{19}$ Students from greater wealth are statistically more likely to attend 4-y colleges than students from less wealthy families. ${ }^{20}$ Students from families with a lower SES base their college choices more on the availability of aid than students coming from higher SES families. Even more importantly, students from lower SES categories are less likely than their higher SES counterparts to complete baccalaureate degrees once enrolled. ${ }^{18,21-24}$ Students from lower SES groups had more interruptions in their baccalaureate degree completion and thus had a lower degree completion rate than students from higher SES groups. ${ }^{20,22}$ Continuous enrollment improved graduation rates by $>30 \% .{ }^{22}$ The inability to complete a bachelor's degree, no matter the reason, reduces earning potential and prevents the ac- 
cumulation of wealth that could be passed on to future generations, thus maintaining inequality.

Presently, the impact of gender, race, and socioeconomic factors on choices of entry-level educational standard for respiratory therapy between an associate degree offered at community colleges to a baccalaureate degree offered at a university is unknown. Therefore, this study utilized the 2009 AARC Human Resource Survey of Respiratory Therapists ${ }^{25}$ to explore the relationships between these variables and choice of associate degree or baccalaureate degree entry-level education. This study addressed whether there were differences between therapists with associate and baccalaureate entry-level respiratory therapy education with regard to (1) gender and race; (2) pursuing higher academic degrees, the highest academic degree achieved, rate of achieving the registered respiratory therapist (RRT) credential, the number of National Board for Respiratory Care (NBRC) specialty credentials, the number of advanced life support credentials, and additional healthcare credentials; (3) wages and primary job title; and (4) the use of respiratory care by protocol and job satisfaction.

\section{Methods}

A secondary analysis of the data collected from the 2009 AARC Respiratory Therapist Human Resource Survey ${ }^{25}$ was used to determine whether there is a relationship between demographic variables and choice of entry-level educational degree for respiratory care. This research was conducted at Rush University (Chicago, IL), and the authors obtained institutional review board approval for the study. The list of variables that was extracted from the 2009 AARC survey were the demographic variables of gender and race; variables linked to education such as respiratory therapy training/education, college degree when eligible for respiratory therapist credentials, currently pursuing a higher academic degree, highest academic degree obtained, NBRC credentials earned, advanced life support credentials, and additional healthcare credentials; employment variables such as wages and job title; and practicerelated variables such as the use of respiratory care by protocol and job satisfaction.

The 2009 AARC Human Resources Survey contained data on gender and race. Gender options were male and female. Survey participants could record their race as Native American or Alaska Native, Asian, Black or African American, Native Hawaiian or Other Pacific Islander, or White. Each of these 5 options had a checkbox for either Hispanic or Latino or Not Hispanic or Latino. Individuals who selected any of the Hispanic or Latino options were classified as Latino and not included in another racial category even if one was selected.
Survey participants identified their respiratory therapy training/education as on-the-job trainee, entry level, or advanced level, eligible for the RRT. They also could select among associate's, bachelor's, or master's as options for the college degree that they earned when they became eligible for their respiratory therapy credential. Options for the highest academic level achieved were some high school, but no diploma; high school diploma or GED; some college, but no degree; associate's degree; bachelor's degree; master's degree; or doctoral degree. A dichotomous yes/no response option was available for a question about pursuing a higher academic degree. Survey respondents who indicated that they were pursuing a higher degree were asked whether it was to advance their respiratory care career or change careers. The pursuit of higher degree analysis only included the data for individuals who planned to remain in the respiratory care profession.

The survey also listed options for credentials from the NBRC, advanced life support, and related healthcare specialties. A sum of each participant's total credentials from the 3 separate categories was computed. The NBRC credential section had responses for certified respiratory therapist (CRT), certified pulmonary function technologist (CPFT), neonatal/pediatric specialist (CRT-NPS or RRTNPS), sleep disorders specialist (CRT-SDS or RRT-SDS), registered pulmonary function technologist (RPFT), and RRT. The advanced life support group included advanced cardiac life support (ACLS), basic cardiac life support (BCLS), neonatal resuscitation protocol (NRP), and pediatric advanced life support (PALS). Finally, the survey listed other specialty credentials such as certified asthma educator, certified cardiographic technician, certified case manager, certified hyperbaric technologist, emergency medical technician, paramedic, registered cardiovascular invasive specialist, registered electroencephalography technologist, registered electrophysiology technologist, registered polysomnographic technologist, registered vascular or cardiac ultrasound credential, and others.

The human resources survey collected several measures of wages. These included hourly base wage; pay differentials for shift, weekend, holiday, and on-call; bonuses; and estimated total wage for the year 2008 in primary, secondary, and third job. This study analyzed only the estimated wage for the primary job. Job titles for the survey participants' primary job were condensed into three main categories to provide a sufficient number of items in each category to conduct the chi-square statistical analysis. The category names followed by the original response variables in parentheses were: leadership (director, clinical specialist, and supervisor), therapist (staff therapist/technician, pulmonary function technologist, and sleep technologist), and educators (instructor/educator and disease manager/patient educator). 
Finally, the analyses included 2 survey elements related to job characteristics. Respondents rated their job satisfaction from 1 to 5, where 1 meant "unsatisfied, I am ready to quit this job" and 5 meant "completely satisfied, I want to stay in this job." They also responded yes or no to the question, "Do you deliver respiratory care by protocol when providing direct patient care?"

Statistical analyses explored the relationship among the study variables and the associate degree and baccalaureate degree entry-levels of respiratory care education with twotailed tests and differences considered to be significant when $P<.05$. The chi-square test was used to assess whether there was any relationship between therapists with associate and baccalaureate entry-level education and respiratory therapists' gender, race, current pursuit of advanced academic degree, highest academic degree, completion of RRT credential, primary job title variable, and use of respiratory care by protocol. Differences between the entry-level education and the total number of advanced respiratory care credentials, total number of additional credentials, total number of advanced academic degrees, and estimated wages from the primary job variables were analyzed by using the Student $t$ test. Finally, Spearman's rho correlation was used to analyze job satisfaction.

\section{Results}

Of the total of 3,139 respiratory therapists who responded to the 2009 AARC Human Resources Survey, 2,461 respiratory therapists $(78.4 \%)$ identified themselves as having an associate or baccalaureate degree at the time they were eligible for their respiratory care credential.

Analysis of the demographic variables of gender and race showed that no statistical difference between therapists with associate and baccalaureate entry-level respiratory therapy education emerged. Race was analyzed initially by using the racial categories from the original survey. However, there were insufficient numbers of respiratory therapists in the Native American or Alaska Native, Asian, Black or African American, and Native Hawaiian or Other Pacific Islander categories to conduct a chi-square analysis. Therefore, the race data were analyzed by looking at whether there were differences between the number of white respiratory therapists and respiratory therapists from all other minority groups (nonwhites). The results are summarized in Table 1.

The next group of research questions evaluated how respiratory care credentials earned differed among therapists with associate degree and baccalaureate degree entrylevel education. According to chi-square test results, significant differences existed in the numbers of therapists who achieved the RRT credential and the highest academic degree achieved. The effect size for the RRT credential was weak $(\varphi=.076)$, with $94 \%$ of the total of
Table 1. Chi-Square Test Results Comparing Gender and Race Variables Among Entry-Level Degrees

\begin{tabular}{lccc}
\hline \hline & $\begin{array}{c}\text { Associate } \\
\text { Degree }\end{array}$ & $\begin{array}{c}\text { Baccalaureate } \\
\text { Degree }\end{array}$ & $P$ \\
\hline Gender & & & \\
Female & 1,216 & 287 & .06 \\
Male & 701 & 201 & \\
Race & & & .14 \\
$\quad$ White & 1,443 & 383 & \\
$\quad$ Nonwhite & 389 & 85 & \\
\hline
\end{tabular}

Table 2. Chi-Square Test Results Comparing Academic Categorical Data for Entry-Level Degrees

\begin{tabular}{lrrr}
\hline \hline & $\begin{array}{c}\text { Associate } \\
\text { Degree }\end{array}$ & $\begin{array}{c}\text { Baccalaureate } \\
\text { Degree }\end{array}$ & $P$ \\
\hline $\begin{array}{l}\text { Registered respiratory } \\
\text { therapist }\end{array}$ & & & \\
$\quad$ Yes & 1,729 & 472 & $.001^{*}$ \\
$\quad$ No & 230 & 30 & \\
Pursuing a higher academic & & & \\
$\quad$ degree for respiratory & & & \\
$\quad$ care career & 379 & 75 & $.03^{*}$ \\
$\quad$ Yes & 1,452 & 389 & \\
$\quad$ No & & & \\
Highest academic level & 484 & 391 & \\
$\quad$ Bachelor & 211 & 107 & \\
Graduate & & & \\
& & & \\
$* P<.05$. & & & \\
\hline
\end{tabular}

baccalaureate entry-level respiratory therapist respondents having the RRT credential compared with $88 \%$ of entrylevel associate degree respondents. There were a greater number of respiratory therapists with an entry-level associate degree pursuing higher academic degrees (20.7\%) than baccalaureate degree entry-level therapists (16.2\%). Among associate degree entry-level therapists who went on to earn baccalaureate degrees, $30.4 \%$ also earned master's degrees compared with only $21.5 \%$ of baccalaureate degree entry-level therapists. However, only $10.8 \%$ of all associate degree entry-level therapists went on to earn graduate degrees after entering respiratory care practice. These results appear in Table 2.

A greater number of baccalaureate entry-level therapists earned respiratory care credentials through the NBRC than their associate degree counterparts. There were no group differences in the numbers of additional credentials (eg, certified asthma educator, certified cardiographic technician, certified case manager, certified hyperbaric technologist, and emergency medical technician) and life support credentials among the 2 different entry-level degree categories. A summary of these results appears in Table 3. 
Table 3. Student's $t$-Test Results Comparing Baccalaureate and Associate Degree Entry-Level Data for Advanced Credentials

\begin{tabular}{|c|c|c|c|}
\hline & $\begin{array}{c}\text { Associate } \\
\text { Degree } \\
(\text { Mean } \pm \mathrm{SD})\end{array}$ & $\begin{array}{c}\text { Baccalaureate } \\
\text { Degree } \\
(\text { Mean } \pm \mathrm{SD})\end{array}$ & $P$ \\
\hline Total NBRC credentials & $1.91 \pm 0.89$ & $2.03 \pm 0.99$ & $.007 *$ \\
\hline $\begin{array}{l}\text { Number of additional } \\
\text { credentials }\end{array}$ & $0.26 \pm 0.54$ & $0.32 \pm 0.59$ & .07 \\
\hline $\begin{array}{l}\text { Number of advanced life } \\
\text { support credentials }\end{array}$ & $2.52 \pm 1.19$ & $2.52 \pm 1.18$ & .96 \\
\hline
\end{tabular}

The next analyses explored differences between therapists with associate and baccalaureate entry-level respiratory therapy education and their estimated wages from their primary job in 2008. The result of the Student $t$ test revealed no statistically significant difference $(P=.35)$ between wages of respiratory therapists' with entry-level baccalaureate degrees $(\$ 63,650$, $\pm \$ 49,848)$ and entrylevel associate degrees $(\$ 61,602, \pm \$ 41,635)$.

The results of chi-square analyses suggested that there was a statistically significant difference between therapists with associate and baccalaureate entry-level respiratory therapy education with regard to primary job title, but not in the use of respiratory care by protocol. More respiratory therapists with baccalaureate entry-level degrees held leadership (40\%) and educator (12\%) primary job titles compared with respiratory therapists with associate degrees with leadership (37\%) and educator $(7 \%)$ titles. As a result, $56 \%$ of entry-level associate degree therapists worked in therapist roles compared with $48 \%$ of the entry-level baccalaureate group. The Cramér's $\mathrm{V}$ for this analysis was 0.078 , indicating a weak effect. The comparison of the 2 different entry-level education groups with their experience in delivering respiratory care by protocol showed that an equal percentage $(67 \%)$ of baccalaureate and associate respiratory therapists were responsible for delivery of respiratory care by protocol. See Table 4 for further details.

Spearman rank-order correlations were conducted to explore the relationship between the respiratory therapists' job satisfaction in their primary job. The results suggested that there was no significant relationship $\left(r_{s}=-0.02\right.$, $P=.33$ ) between associate and baccalaureate entry-level education with regard to job satisfaction.

\section{Discussion}

One concern about advancing the entry-level education for respiratory therapists is that the applicant pool may not be as diverse if the entry-level requirement is raised from
Table 4. Chi-Square Results Comparing Baccalaureate and Associate Degree Entry-Level Data Among Job Roles

\begin{tabular}{lccc}
\hline \hline & $\begin{array}{c}\text { Associate } \\
\text { Degree }\end{array}$ & $\begin{array}{c}\text { Baccalaureate } \\
\text { Degree }\end{array}$ & $P$ \\
\hline $\begin{array}{l}\text { Deliver respiratory care by } \\
\text { protocol }\end{array}$ & & & .98 \\
$\quad$ Yes & 1,251 & 323 & \\
$\quad$ No & 621 & 160 & $.002^{*}$ \\
Primary job category & & & \\
$\quad$ Leadership (director, \\
$\quad$ clinical specialist, and \\
$\quad$ supervisor) \\
$\quad$ Therapist (staff therapist/ \\
$\quad$ technician, pulmonary \\
$\quad$ function technologist, \\
$\quad$ and sleep technologist)
\end{tabular}

an associate degree to a baccalaureate degree. In the discussion following a recent article in this journal, Kacmarek addressed the need to have therapists enter the profession with baccalaureate degrees. ${ }^{26} \mathrm{He}$ noted that moving toward an entry-level baccalaureate degree would change the demographics. The findings from this study's analyses using the 2009 AARC Human Resources Survey call this assumption into question. Similar demographic proportions for gender and white race emerged among respondents who earned associate and baccalaureate degrees when they completed their entry-level education. These findings show that the current baccalaureate degree programs attract therapists with similar diversity to those in associate degree programs.

Several authors report that, currently, women complete more bachelor's degrees than men. ${ }^{9-13}$ Findings from this present study are consistent with the literature. It is noteworthy, however, that the percentage of men who completed baccalaureate degrees was greater than the percentage of men who completed associate degrees. The demographic shift in baccalaureate completion from men to women occurred in the 1980s. ${ }^{9}$ The specific age of those who earned entry-level baccalaureate degrees was not evaluated in this study. Thus, the relatively greater proportion of men having baccalaureate compared with associate degrees in this study may not reflect the current trends across all disciplines.

The analysis of racial diversity showed a similar proportion of whites and nonwhites among therapists who earned associate degrees and baccalaureate degrees upon entering the profession. The percentages of whites who enrolled in the entry-level associate and baccalaureate de- 
gree programs were $79 \%$ and $82 \%$, respectively, which mirrors the general United States population. Whites comprise $77.9 \%$ of the total population as reported by the United States Census Bureau's data from 2012 (http:// quickfacts.census.gov/qfd/states/00000.html, Accessed February 9, 2014). This study's high percentage of white therapists created too many cells in the chi-square analysis with low expected values to conduct separate analyses for African-American, Hispanic, Asian, and Native American/Alaskan Native categories. Thus, the distribution of therapists among minority categories for associate and baccalaureate entry-level programs could not be analyzed.

The similar proportion of nonwhites for both entry-level degree programs found in this study is consistent with the broader literature on race and degree completion. Although there are higher levels of poverty in children from AfricanAmerican, Native American/Alaska Native, Hispanic, and Native Hawaiian or Other Pacific Islander minority groups, ${ }^{27}$ it is tempting to assume that baccalaureate degree completion is influenced by race. In contrast, the literature supports that a family's socioeconomic status rather than race likely mediates acquisition of a baccalaureate degree. ${ }^{17,18,22-24}$ In practical terms, white students from lower SES families are less likely to pursue baccalaureate degrees, and nonwhite students from higher SES families are more likely to pursue baccalaureate degrees.

The database used in this study did not contain any information about the therapists' socioeconomic (SES) status at the time they entered the respiratory care profession. Thus, no conclusions can be drawn about how SES affected the choice of entry-level degree. The preponderance of associate degree entry-level programs did not allow individuals who might have preferred a baccalaureate degree to choose that option. Analyses from this study demonstrated that a greater number of entry-level associate degree graduates $(20.7 \%)$ were pursuing advanced degrees compared with baccalaureate degree colleagues (16.2\%). Of those entry-level associate degree therapists who completed their baccalaureate degree, $30.4 \%$ went on to complete their master's degree versus only $21.5 \%$ of entrylevel baccalaureate therapists. Thus, the historical data support the desire for therapists to have advanced degree options. Some might argue that the current system of completing an associate degree first and then pursuing a baccalaureate degree is satisfactory. However, the number of individuals who complete baccalaureate degrees may be lower through this pathway as the number of times an individual needs to start and stop education reduces the chances of completing a baccalaureate degree..$^{22}$

Although the direct impact of socioeconomic status on degree completion could not be assessed, data from the 2009 United States Census Bureau indicates that individuals with a baccalaureate degree earn $\$ 13,700 / y$ more on average than individuals with associate degrees. ${ }^{13}$ The 2008 estimated wages for entry-level associate and baccalaureate degrees therapist did not differ from each other. However, the 2009 AARC Human Resources Survey reveals that the job titles of educator, director, and supervisor are linked to both greater numbers of higher academic degrees and overall higher salaries, respectively. ${ }^{25}$ Thus, a higher salary for a therapist with a baccalaureate degree may not be present at entry level. Rather, the advanced degree provides therapists with foundational skills to prepare for leadership positions. The salary increase comes later and is associated with the leadership roles. Thus, a therapist with an entry-level baccalaureate degree has the potential to improve SES in the longer-term.

The primary question posed in this study was whether increasing the entry-level degree requirement to a baccalaureate degree would have a negative impact on the diversity of the respiratory care profession. The results above indicate that gender and the number of therapists from minority backgrounds were similar among the 2 different categories of entry-level education studied. Variables that could not be assessed were whether the distribution of therapists within minority groups differed among entrylevel education level and whether there were fewer individuals from lower socioeconomic backgrounds. Some might argue that balanced gender and race sufficiently satisfy diversity concerns. Others might counter that balanced SES representation in the respiratory therapist workforce would enhance the ability of therapists to understand the specific challenges patients in low-SES environments face and identify potential solutions that those from other backgrounds cannot. Whether there is or is not an imbalance of SES status among entry-level baccalaureate therapists remains unknown.

Although a comprehensive discussion of how to develop greater diversity for the respiratory care profession is beyond the scope of this paper, the benefits of a diverse respiratory care workforce must be considered. Less and lower quality healthcare is received by African Americans, Native Americans, and Hispanic Americans. ${ }^{14}$ Therapists representative of these minority groups can help colleagues and organizations both understand the problems that limit healthcare for these individuals and design systems that will close the health disparities gap. Further, patients need healthcare providers who can speak the same language and dialect as they do. Among the numerous strategies cited by the Sullivan Commission on Diversity in the Healthcare Workforce was the importance of having diverse faculty to help recruit and retain students from minority backgrounds. ${ }^{14}$

One point of controversy regarding the move to an entry-level baccalaureate degree is that a shortage of therapists would occur. Individuals who are attending community colleges to obtain their education may choose an entrylevel associate degree option for economic reasons. 
However, many students enter academia with career aspirations to obtain baccalaureate and graduate degrees. Thus, programs that offer baccalaureate degrees would likely be successful recruiting equally diverse students in regards to gender and race. The difference that cannot yet be answered is whether there would be significant differences in SES of future therapists.

Additional questions related to credentials and job roles were also addressed in this study. Individuals with entrylevel baccalaureate degrees more often had the RRT credential and had a greater number of credentials from the NBRC. That said, it should be noted that the NBRC conducted an evaluation of the first-time pass rates on the CRT, written RRT, and clinical simulation exams. ${ }^{28}$ The results indicated that exam scores from graduates of baccalaureate degree programs differed significantly from associate degree graduates, but the effect size of the difference was too small to be practically significant. At first glance, this finding may appear as though associate and baccalaureate entry-level therapists have equivalent respiratory care skills. However, an advanced degree provides respiratory therapists with the potential to master more clinical skills, critical thinking, participation in more complex and higher clinical skill procedures, and understanding clinical research. ${ }^{1}$ The current NBRC exams do not measure the writing, research evaluation, and other skills offered in baccalaureate programs. Thus, a different assessment would be needed to evaluate whether the entrylevel associate and baccalaureate respiratory care preparation are equivalent with each other.

The analyses in this study showed that entry-level baccalaureate degree therapists had more NBRC credentials such as the RRT-NPS, RPFT, or RRT-SDS. These credentials imply that therapists have more advanced knowledge that could lead to enhanced clinical skills and improved patient care. The precise reason for the increased number of advanced credentials was not evaluated. Potential explanations may include a self-selection bias of a commitment to continuing education by baccalaureate degree therapists, greater emphasis on obtaining advanced credentials in baccalaureate programs, or perhaps greater contact time with faculty over the course of the baccalaureate degree program. The baccalaureate entry-level degree participants did not differ in the number of other healthcare credentials that were earned nor the number of advanced life support credentials. Furthermore, job-related variables such as job satisfaction and performing respiratory care by protocol did not differ among groups.

In summary, the analysis of data from the 2009 AARC Human Resources Survey indicated that there was similar diversity in gender and white versus nonwhite therapists among associate and baccalaureate entry-level education programs. The impact on SES diversity and resultant changes to the delivery of care to patients remains un- known. The advance to a baccalaureate entry-level degree has the potential to enhance socioeconomic standing of individuals who enter the profession by promoting growth in a career ladder, assist in earning more specialty credentials, and develop more research and critical thinking skills, which has the potential to improve patient care.

\section{Limitations}

This study was a secondary analysis of the 2009 AARC Human Resource Respiratory Therapist Survey, so limitations of the primary study apply to the present study. ${ }^{25}$ Many respiratory therapists did not respond to the survey. Additionally, there were 3,942 people who accessed the survey, but only 3,139 submitted responses. There were 112,700 respiratory therapists in 2010 according to the United States Bureau of Labor Statistics (http://www.bls. gov/ooh/healthcare/respiratory-therapists.htm, Accessed November 10, 2013). Thus, the respondents for this survey represent only $2 \%$ of the total population. Furthermore, the responses from respiratory care educators, hospital directors, AARC members, and asthma educators were overrepresented and likely biased the results. In addition, analyses conducted in this study such as the need to group job titles into categories and small numbers in the individual minority race categories contributed to potential sources of error.

Furthermore, the exact number of baccalaureate respiratory care programs and their locations throughout the United States in 2008 is not known. Additionally, the proximity of survey participants to a baccalaureate entry-level program at the time of entry-level education could not be determined. Thus, it is not known whether individuals who may have wanted to pursue a baccalaureate entry-level degree could have easily chosen one.

\section{Conclusions}

The study showed that the proportions of women and minorities who graduated from entry-level associate and baccalaureate programs were similar among respondents from the 2009 AARC Human Resources Survey. The impact of SES on the diversity of respiratory therapists could not be assessed with the available data. The overall wages between baccalaureate and associate degree entry-level therapists did not differ; however, therapists with baccalaureate degrees obtained upper level management and education positions that were associated with higher wages and succeeded in obtaining more professional credentials. Toward that end, earning a baccalaureate degree enhanced the opportunity to improve SES. Therefore, increasing the entry-level baccalaureate educational standard for respiratory therapy would not necessarily harm the diversity of the profession. 


\section{ENTRY-LEVEl EDUCATION AND Diversity of RTs}

\section{REFERENCES}

1. Barnes TA, Kacmarek RM, Kageler WV, Morris MJ, Durbin CG Jr. Transitioning the respiratory therapy workforce for 2015 and beyond. Respir Care 2011;56(5):681-690.

2. McHugh MD, Kelly LA, Smith HL, Wu ES, Vanak JM, Aiken LH. Lower mortality in magnet hospitals. Med Care 2013;51(5):382-388.

3. Aiken LH, Clarke SP, Cheung RB, Sloane DM, Silber JH. Educational levels of hospital nurses and surgical patient mortality. JAMA 2003;290(12):1617-1623.

4. Friese CR, Lake ET, Aiken LH, Silber JH, Sochalski J. Hospital nurse practice environments and outcomes for surgical oncology patients. Health Serv Res 2008;43(4):1145-1163.

5. Estabrooks CA, Midodzi WK, Cummings GG, Ricker KL, Giovannetti P. The impact of hospital nursing characteristics on 30-day mortality. Nurs Res 2005;54(2):74-84.

6. Tourangeau AE, Doran DM, McGillis Hall L, O'Brien Pallas L, Pringle D, Tu JV, Cranley LA. Impact of hospital nursing care on 30-day mortality for acute medical patients. J Adv Nurs 2007;57(1): 32-44.

7. Lundy VC. The significance of interactions: understanding gender, ethnicity/race, and socioeconomic status as related to the likelihood of bachelor's degree completion (2010 doctoral dissertation). http:// repository.upenn.edu/edissertations/128/. Accessed June 2, 2014.

8. Perna LW. The benefits of higher education: sex, racial/ethnic, and socioeconomic group differences. Rev High Educ 2005;29(1):23-52.

9. Goldin C, Katz LF, Kuziemko I. The homecoming of American college women: the reversal of the college gender gap. J Econ Perspect 2006;20(4):133-156.

10. Buchmann C, DiPrete TA. The growing female advantage in college completion: the role of family background and academic achievement. Am Sociol Rev 2006;71(4):515-541.

11. Jacobs JA. Gender and the stratification of colleges. J Higher Ed 1999;70(2):161-187.

12. Snyder TD, Dillow SA, Hoffman CM. Digest of education statistics 2008. (NCES 2009-020). Washington, DC: National Center for Education Statistics, Institute of Education Sciences, U.S. Department of Education; 2009.

13. Baum S. Education pays, 2010: the benefits of higher education for individuals and society. Trends in higher education series. http:// trends.collegeboard.org/sites/default/files/education-pays-2010-fullreport.pdf. Accessed June 2, 2014

14. Sullivan Commission on Diversity in the Healthcare Workforce. Missing persons: minorities in the health professions. Durham, NC: Duke University School of Medicine; 2004.
15. Kao G, Thompson J. Racial and ethnic stratification in educational achievement and attainment. Annu Rev Sociol 2003;29:417-442.

16. Thompson M, Gorin JS, Obeidat K. Understanding differences in postsecondary educational attainment: a comparison of predictive measures for black and white students. J Negro Educ 2006;75(3): 546.

17. DesJardins SL, Ahlburg DA, McCall BP. The effects of interrupted enrollment on graduation from college: racial, income, and ability differences. Econ Educ Rev 2006;25(6):575-590.

18. Titus MA. Understanding college degree completion of students with low socioeconomic status: the influence of the institutional financial context. Res High Educ 2006;47(4):371-398.

19. Krieger N, Williams DR, Moss NE. Measuring social class in US public health research: concepts, methodologies, and guidelines. Annu Rev Publ Health 1997;18(1):341-378.

20. Terenzini PT, Cabrera AF, Bernal EM. Swimming against the tide: the poor in American higher education. Research report no. 2001-1. New York: The College Board.

21. Cameron SV, Heckman JJ. The dynamics of educational attainment for black, hispanic, and white males. J Polit Econ 2001;109(3):455499.

22. Goldrick-Rab S. Following their every move: an investigation of social-class differences in college pathways. Sociol Educ 2006;79(1): 67-79.

23. Vartanian TP, Karen D, Buck PW, Cadge W. Early factors leading to college graduation for Asians and non-Asians in the United States. Sociol Quart 2007;48(2):165-197.

24. Walpole M. Socioeconomic status and college: how SES affects college experiences and outcomes. Rev High Educ 2003;27(1):4573.

25. Shaw RC, Traynor C, Benavente JL. 2009 AARC human resource survey of educational programs. Irving, TX: American Association for Respiratory Care; 2009.

26. Kacmarek RM. Mechanical ventilation competencies of the respiratory therapist in 2015 and beyond. Respir Care 2013;58(6):10871096.

27. KewalRamani A, Gilbertson L, Fox MA, Provasnik S. Status and trends in the education of racial and ethnic minorities (NCES 2007039). U.S. Department of Education. Washington, DC: National Center for Education Statistics; 2007.

28. Shaw RC, Traynor C. Effects from education program type on RRT candidate outcomes. Olathe, Kansas: National Board for Respiratory Care; 2010;1-20.

This article is approved for Continuing Respiratory Care Education credit. For information and to obtain your CRCE

(free to AARC members) visit www.rcjournal.com

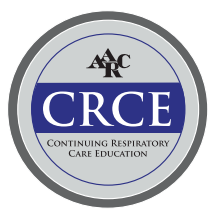

